\title{
Evolutionary Professionalism of Civil Servants
}

\author{
Lan Zhang \\ Jinan University \\ Guangzhou, China
}

\begin{abstract}
In recent years, theoretical researches on professionalism of civil servants have been done. After the Civil Servant Law is enacted, the civil servant system implements the "double-track system" promotion method. Some scholars observe it seems the objective of "separation of political officials and civil officials" is closer and the professionalism of civil servants should be included in the schedule. According to the practical experience that the political power continuing the "Utopia" idea of Sun Yat-sen refers to the western civil servant system, the differences between the civil servant system in our country and the western civil servant system are analyzed. The process should be evolutionary with the professionalism of secretaries and administrative assistants prior to the rest.
\end{abstract}

Keywords-Civil Servant Law; western civil servant system; professionalism

\section{INTRODUCTION}

The professionalism of civil servants originates from bureaucracy of Weber. Max Weber proposes in his Bureaucracy: civil servants become a profession that requires trained officials; officials are appointed for lifetime; they have fixed amount of salary and retirement protection; officials undertake lifelong career in the hierarchical organization system and follow the promotion route from low to high. 'Weber's idea in official professionalism is widely accepted by the western world and becomes one of the core contents of western civil servant system. Some scholars address the professionalism of civil servants can effectively prevent corruption, improve administrative efficiency of government and avoid superfluous staff in organizations.

\section{ORIGIN AND CONNOTATION OF PROFESSIONALISM OF CIVIL SERVANTS}

Tan Gongrong proposes in Professionalism of Civil Servants: Comparison of Origin, Connotation and Pattern ${ }^{2}$ that the origin of civil servants reveals civil servants are professional at first. The professional structure of modern civil servants originates from Prussia. In order to weaken feudal privileges of nobilities, the central government

Jing Ting. Development Direction of Professionalism of Chinese Civil Servants [J], Journal of Nanjing Normal University (Social Science Edition), May 2007, the 3rd Edition, (12)

Tan Gongrong. Professionalism of Civil Servants: Comparison of Origin, Connotation and Pattern [J], Chinese Public Administration, February 2009, (106-110) administrates provinces through appointing and dismissing government functionaries who are responsible for the central government. The bureaucracy of Prussia clearly indicates officials are national public servants through legislation and determines certification authorities of civil servants at different levels in accordance with particular laws and orders. Primary civil servants are appointed after passing the examination. They have to attend necessary training to enter the senior public servant system. The status of civil servants and the execution of power are restricted by systems. ${ }^{3}$

In the management of East India Company, Britain strengthens personnel management through legislation and recruits civil servants through training and examination, uses employment through examination to replace appointment through gifting and establishes effective administrative mechanism. The professionalism of civil servants in America is similar. The Congress passes Civil Servant Law that determines basic principles of civil servant system. For example, the civil servants must be selected through open competitive examination; civil servants hold an attitude of "political neutrality" toward the two parties and are forbidden to participate in politicking and provide political donations; "Civil Servant Committee" is established pursuant to law, responsible for the unified management of national civil servants. In the implementation of civil servant system, America brings merit system and classification system in the government personnel administration. The professionalism develops steadily. The system framework of professionalism of civil servants is established. ${ }^{4}$

Civil servants are scientific or professional government functionaries to provide technical support for the government. Civil servants in western countries are decision-making consultants of governments, not a symbol of power but a special profession. In short, the professionalism of civil servants has necessary elements: first, require professional literacy, namely civil servants must have professional ability proposed by administrative department; second, strengthen the training of civil servants and make them have working ability required by administrative department; third, civil servants must have enough sense of professional identity, sense of mission and

Tan Gongrong. Professionalism of Civil Servants: Comparison of Origin, Connotation and Pattern [J], Chinese Public Administration, February 2009, (106-110)

46 Idem 
responsibility and superior spirit and quality; finally, in mutual collaboration, civil servants establish unique occupational culture and have more sense of honor.

\section{Two PATTERNS OF PROFESSIONALISM OF CIVIL SERVANTS}

It proposes in the Professionalism of Civil Servants: Comparison of Origin, Connotation and Pattern that the professionalism of western civil servants has two patterns including "profession type" and "post type".

"Profession type" is indenture system. Civil law countries such as France and Germany stress civil servant relation is "special power relation". Civil servant is a profession and has contractual relationship with the country instead of simple employment relationship. Their behaviors are restricted by Administrative Law. Civil service examination and professional training in France and Germany are directly organized by the government. People directly become senior civil servants if they are qualified after training. The organization of public servant training in France directly subordinates to central government of France under the administration of prime minister. Permanent tenure in office is provided for civil servants, which are regarded as lifelong career. The country has perfect legal system to restrain behaviors of civil servants.

"Post type", just as its name implies, regards civil servant as one of the ordinary professions and only has employment relationship with the government. In Britain, ministers serve the cabinet, civil servants serve ministers. The rights and status are nearly the same with employees in private enterprises. Britain and America implement "post system" for civil servants. The promotion depends on composition instead of seniority. The government can avoid superfluous staff.

The two patterns of "profession type" and "post type" have no comparability. They are formulated according to different legal systems and national conditions. Moreover, they are not entirely different without relationship and reference.

\section{CHINA CANNOT CARRY OUT COMPREHENSIVE PROFESSIONALISM OF CIVIL SERVANTS}

The administration of civil servants in our country has been scientific, democratic and legal. The implementation of Civil Servant Law has higher requirements for quality of civil servants. Under the comprehensive legal norms of cadre personnel management, the classification of civil servants' functions is more scientific and succeeds in meeting the demand of departments with strong professional skills and the demand of government functionaries at all levels. Although the classification of civil servants' functions in Civil Servant Law is far apart from the objective of "separation of political officials and civil officials" expected by scholars, ${ }^{5}$ scholars have seen the

Xie Wei, Ding Baohua. Development Paths of Chinese Civil Servant System [J], Social Sciences: Beijing, the 2nd Issue of 2006, (109) hope to realize professionalism of civil servants. Civil servants in our country are different from western civil officials, so it is unrealistic to implement comprehensive professionalism of civil servants.

In government, it is necessary to realize professionalism of clerks assisting leaders. They are a part in the government system. Civil servants in our country refer to the staffs that perform public duty in accordance with law, are brought into national administrative establishment and the salary and welfare of whom are shouldered by national finance, the joint name of leading cadres and clerks. Western civil officials are not equal to Chinese civil servants.

First, connotations of Chinese and western civil servants are different. Western civil servants are civil officials under leadership. Civil officials often serve different leaders. China is on the contrary. Chinese civil servants refer to leading cadres at all levels and clerks including office secretaries and administrative assistants. The professionalism can be carried out for office secretaries and administrative assistants instead of government officials. Emphasizing the professionalism of civil servants onesidedly before knowing clearly about the constitution of Chinese civil servants completely fails to conform to China's national condition.

Second, Chinese and western political systems are different. Firstly, China implements dual-executive system, including the leaderships of the party and the government. Political leadership includes chief leader and deputy leader, who are leading cadres. For example, provincial governor and vice-governor, mayor and deputy mayor, secretary general in the government are leading cadres. Secondly, the Party committee has members of the standing committee, seven to nine in the central government and a dozen in local areas. Leaders in the same province are at the same level. Thirdly, the government leadership is collective leadership, which is different from the American presidential system that the president is the head of the state and the government at the same time. Policies and guidelines of our country are wisdom crystallization of collective leadership that the party and government leaders are members of the leading group. It determines civil servants cannot be summarized as political officials and civil officials. The western cabinet system is essentially different from polity of our country. Western countries like America implement presidential system that president is the head of state and government. Differently, the political system in our country can only be divided by leadership of the party committee and administrative leadership.

\section{Professionalism OF SOME Civil SERVANTS}

With the implementation of Civil Servant Law, the civil servant administration in our country becomes scientific, democratic and legal. Ability building is the trend of the times and should run through the construction of civil servants. China should first realize professionalism of secretaries and clerks and select civil servants through examination because it conforms to China' national conditions. 
The proposition of professionalism has positive influence on improving work efficiency and governing capacity of the government. Although we can neither copy western civil service system and administrative system nor solve all problems in political restructuring through professionalism, the professionalism process can be evolutionary in the government, such as first realize the professionalism of secretaries.

\section{A. Necessity for Professionalism of Secretaries}

Secretary group or agency in our country always expands and returns in history.

Before the Revolution of 1911, central governments have secretary agencies. Qing dynasty has office of prime minister which is the general office of emperor. Prime minister in ancient China is similar to today's director of the general office. In the Western Han Dynasty, the office of prime minister has more functions and adds the function of government, so it is brought into the outer palace and subject to the government system. The imperial palace has minister office which is the secretary agency of central government. In continuous development, it adds rights of rewarding and punishing officials of all ranks and descriptions and develops into organ of power and government body like the office of prime minister. Cao Pi establishes central secretariat, which is responsible for drafting imperial edicts and memorial to the emperor and hasn't real power. In Wei, Jin, Northern and Southern Dynasties, the powers of central secretariat further expand. Although ministry of supervision, department of state affairs and central secretariat are established to divide power and they restrict and assist each other, in Tang dynasty, they expand to central government body. Emperor of Tang dynasty has to establish central secretary agencies and employ Hanlin Scholars who form cabinet in Ming dynasty and it develops into central confidential secretary agency, the responsibility range of which expands continuously. Initially, it collects and reads memorial to the emperor, serve as counselor and handle government affairs. It gradually transforms into agency of government affairs with increasing power and even threatens imperial power. The central secretary agency loses its real meaning again. In Qing dynasty, Kangxi Emperor establishes Nanshufang, Yongzheng Emperor establishes Junjichu, in order to assist the emperors. History has a striking resemblance. When assisting emperors, the power of Junjichu expands continuously. It participates in government and political affairs and has the power of personnel administration and becomes the center of decision making. Junjichu is forbidden during the Revolution of 1911. The secretary agency during feudal autocracy no longer exists. Central secretary agencies of feudal dynasties have periodic evolution of establishing, expanding, weakening, disassembling or transforming. It includes the expansion and return of secretary agencies and secretaries.

\section{B. Practice of Secretary Professionalism}

Western civil servant system plays an important role in the construction of political system in Chinese history. Civil officials in western countries originally refer to "civil waiter", "civil servant" and have nothing to do with "officer". Capitalist countries divide government officials into political officials and civil officials. Political officials refer to those advance and retreat with government together in capitalist countries. Civil officials refer to government staffs that do not advance and retreat with government together, namely the so-called "permanent civil officials". Civil servant system in capitalist countries is the management system related to examination, appointment, assessment, supervision, promotion and demotion, salary, rewards and punishment, retirement and removal of government civil officials. ${ }^{6} \mathrm{Western}$ civil servant system is an enormous and complex system. Scientific operation mechanism plays a vital role in guaranteeing civil officials are highly capable, excellent, honest and efficient.

Political leaders before Sun Yat-sen such as Liang Qichao and Yan Fu have noticed western civil servant system avails improving administrative efficiency and maintaining political civilization. It forms sharp contrast with Chinese backward bureaucracy. He brings the concept of public servant in the system construction. The concept refers to western modern political theories and systems and conforms to China's national conditions. Sun Yat-sen integrates western civil servant system with traditional Chinese people-based thought and forms new political idea to establish Nanjing Provisional Government that implements presidential system. The Office of President has secretariat and one secretary general who assumes overall responsibility of handling affairs in the Office and assists the president. Several secretaries are provided to assist the secretary general. The secretariat drafts documents, deals with letter missives and handles daily routines as well as proposes suggestions related to national welfare and the people's livelihood for the president and the secretary general. Generalissimo is the head of state and government, directly governs and commands nine administrative departments of government. Each department has special secretary agency of Chengzheng department, also called secretariat. One secretary general executes the command, handles affairs in department and takes charge of confidential documents.

After the Revolution of 1911, during the Northern Warlords, it continues the governing thought of Sun Yat-sen, western civil servant system and the idea of "separation of the three powers" but it exists in name only.

The secretary agency during the Northern Warlords is independent from department of government affairs. The secretariat in the Office of President has one secretary general, several consultants, secretaries and general protocol officer. The secretary general assists the president in handling affairs. The State Council also has secretariat with secretary general. Secretary agency of the congress is perfection on forms, divides into senate and House of Representatives which are legislative bodies and have

6 Lei Xian. Discussion on Western Civil Servant System [J], Journal of Central Leadership Institute of Politics and Law, Jul.5, 1995, (55) 
secretariats with one secretary general respectively, several secretaries and departments to handle affairs.

Secretaries during the Northern Warlords belong to senior civil servants with high status. They are divided into two types, first is the senior secretaries including secretary general and secretaries, similar to political officials in the western civil servant system; second is ordinary secretaries, similar to civil officials in western countries. On appointment forms and procedures, Beiyang Government follows western civil servant system and inherits experience of secretary selection in Chinese history. It selects talents through examination and values quality and ability of secretaries.

The reference and application of western political system especially civil servant system is most thorough in Chinese history. The regime is overthrown, so making western systems serve China fails to conform to China's national conditions. From feudal period to the Revolution of 1911, secretary agencies completely copy western civil servant system. Results indicate they fail to conform to national conditions.

\section{Professionalism of Secretary in the New Period}

The professionalism of civil servants in western countries integrates legislative regulation, scientific employment with secretary training. It is also applicable to the professionalism of secretaries and administrative assistants in China.

1) “Double-track system" promotion method: Before the implementation of Civil Servant Law, leading cadres and office clerks are in the same promotion system. Secretaries of top leaders are at the inferiority position because they are promoted to cadres of division level at most regardless of their seniority and level. Reputation, status and level of deputy leaders are restricted, so secretaries of leading cadres position the career objective as becoming leaders who grasp real power. Under the circumstances, occupational culture and identity valued in secretary professionalism in western countries are out of the question. Leading cadres have different assignment of responsibility from secretaries and administrative assistants and they are dispensable in the administrative operation. Secretaries and administrative assistants should have systematic and professional skills and knowledge as well as skillful operation level. The execution of duties such as "writing, handling, planning and administration" ${ }^{7}$ requires sense of identity, sense of mission and sense of honor for the profession. They should regard it as lifelong career, plan reasonably and be down-to-earth to win reputation.

Article 14 of Civil Servant Law stipulates: The state adopts a classified system for posts of civil servants. The civil servant posts shall, according to the nature, features and necessity of administration of civil servant posts, be

Yan Hua. Senior Secretary and Administrative Assistant (the 2nd Series) [M], Guangzhou: Jinan University Press, 2012: 1 classified into such categories as comprehensive administrators, technological professions and administrative law enforcers. The State Council adds any other category of posts for those with positional peculiarities. "Double-track system" promotion method that attaches equal importance to position and class of position expands the channel for professionalism of civil servants. Although civil servants cannot get promoted on position, they acquire "the second channel" through promotion of class of position. It expands the incentive and safeguard mechanism of civil servants and breaks through the "official standard" idea and changes the situation of "tremendous people squashing in official circles". ${ }^{8}$

2) Diversification of employment examination: Civil Servant Law stipulates supplementary posts implement appointment system. Chapter XVI of the Civil Servant Law stipulates requirements and scope of responsibilities of post employment, "A state organ may, according to the need of work, adopt an appointment system on those posts with strong specialty and with supplementary features upon the approval of the administrative department of civil servants above the provincial level"; "Where a state organ employs civil servants, if may conduct an open invitation for employment with reference to the procedure for civil servant examination and recruitment, or may make appointment through a direct selection of those who satisfy the requirements"; "Where an organ employs a civil servant, a written contract of employment shall be concluded so as to clarify the rights and obligations of the organ and the civil servant employed according to the principle of equality, willingness, consensus reached through consultation. The contact of employment may be altered or canceled upon the consensus of both parties through consultation."9

Special provisions on appointment system in Civil Servant Law reflect the flexibility of appointment system and provide legal basis for behaviors of government employees. Supplementary posts in the appointment system include secretary, court clerk and those responsible for document management, distribution and data entry. The new system lowers the employment costs of organs, improves employment mechanism. The appointment system becomes flexible. ${ }^{10}$

3) Secretary ability building: "Ability building is the trend of the times and should run through the construction of civil servants." 11 Ability level of secretary and administrative assistant influences administration level and

8 Zhang Ziliang. Ability Building and Professional Development of Civil Servants: Civil Servant Law Expands New Space for Ability Building of Civil Servants, Public Administration and Law [J], 2006, 9(34)

$9 \quad$ Xie Wei, Ding Baohua: Development Paths of Chinese Civil Servant System: Thorough Analysis on Civil Servant Law, Social Sciences [J], 2006(109-110)

10 Xie Wei, Ding Baohua: Development Paths of Chinese Civil Servant System: Thorough Analysis on Civil Servant Law, Social Sciences [J], 2006(110)

11 Zeng Qinghong. Speech at the National Conference on the Implementation of the Civil Servant Law [R], Sept.20, 2005, (80) 
capacity. Secretary system serves government administration system efficiently. The improvement of secretary system and ability avails the enhancement of administration system and level. If secretaries have low work efficiency and fail to meet administration requirements, all kinds of corrupt practices will prevail and problems will appear in the large system.

Many people believe secretary system handles affairs under the ruling system and refers to a subsystem that fulfills tasks assigned from top to bottom and submits reports for approval and then waits for the next task with linear operation. In reality, secretary system and ruling system have mutual effects. Departments and bureaus subordinate to the government at all levels have secretary agencies. They form a complicated net. One secretary agency cannot connect all governing agencies. Secretary agency of central government is responsible for central government and directly connects with local government and departments or indirectly connects through secretary agencies. In investigation, research, supervision, confidentiality and letter petition and stability maintenance, secretaries and staffs similar to secretaries have extensive participation. They are indispensable for ruling officials. Information provided by secretary agencies and the relationship with subordinate units and the mass are ruling foundations.

Chairman Mao is the first secretary of the first session after the founding of CPC. The secretary agency develops into the leading body of the state. It faces numerous and jumbled work contents and constantly expanding work scope and consists of functional departments with professionals. Because the secretary agency established first develops into leading body that deals with problems related to national economy and the people's livelihood, inevitably, the ruling system depends on and attaches importance to secretary system. It is not empty talk that the improvement of secretary ability can improve governing capacity. It is not alarmism that unqualified secretary agency will damage governing capacity.

Ability training and improvement of professional skills need effective training. However, the secretary training, especially the training of secretaries in civil servants has defects.

4) Administrative college in France and senior secretarial college in China: The training of civil servants has legal basis: article 27 of the Constitution stipulates, "All state organs carry out the principle of simple and efficient administration, the system of training functionaries and appraising their performance".

After being employed by state administrative organizations through examination, civil servants shall attend training for no less than ten days. Only qualifiers can take office and enjoy administrative level. Centralized training combines with post internship. The training includes off-job training and on-the-job training. Off-job training has various forms, including seminar, diploma education in colleges and overseas training. In off-job training, the most important problem is how to achieve the training effects with strong practicality and high theoretical level when civil servants leave the post and devote to learning, and civil servants, government departments and training units input enormous human resources, material resources and financial resources. High requirements are proposed for training institutions.

Civil servant training in China is under integrated management of personnel departments in governments at all levels. Training institutions of civil servants include schools of administration, Party school, colleges for training managerial personnel, training center and colleges. Administrative colleges in France train permanent civil servants and the training is systematic, integral and practical. Students of administrative colleges receive systematic and formal education and get internship opportunity in organs and work together with administrative leaders and experienced predecessors. Senior administrative officials such as provincial governors and ambassadors manage and assess the practice regularly. The way that combines theory with practice is worth learning but difficult for us to learn, because the secretary science in colleges of our country belongs to vocational education and colleges are incompetent to train senior secretaries. At present, few colleges can employ secretaries with high educational level. The construction of secretary specialty fails to thoroughly connect with provincial and municipal governments.

\section{CONCLUSION}

The constitution of civil servants is special and must realize evolutionary and one-sided professionalism. Division of labor between party and government is the key to political restructuring in our country. The professionalism of civil servants proceeds steadily under the division of labor between party and government and the change of government functions.

\section{REFERENCES}

[1] Jing Ting. Development Direction of Professionalism of Chinese Civil Servants [J], Journal of Nanjing Normal University (Social Science Edition), May 2007, the 3rd Edition, (12)

[2] Tan Gongrong. Professionalism of Civil Servants: Comparison of Origin, Connotation and Pattern [J], Chinese Public Administration, February 2009, (106-110)

[3] 6 Idem

[4] Xie Wei, Ding Baohua. Development Paths of Chinese Civil Servant System [J], Social Sciences: Beijing, the 2nd Issue of 2006, (109-110)

[5] Lei Xian. Discussion on Western Civil Servant System [J], Journal of Central Leadership Institute of Politics and Law, Jul.5, 1995, (55)

[6] Yan Hua. Senior Secretary and Administrative Assistant (the 2nd Series) [M], Guangzhou: Jinan University Press, 2012: 1

[7] Zhang Ziliang. Ability Building and Professional Development of Civil Servants: Civil Servant Law Expands New Space for Ability Building of Civil Servants, Public Administration and Law [J], 2006, 9(34)

[8] Zeng Qinghong. Speech at the National Conference on the Implementation of the Civil Servant Law [R], Sept.20, 2005, (80) 